\title{
Spaceborne radar measurement of wind velocity over the ocean- an overview of the NSCAT scatterometer system
}

David G. Long

david_long@byu.edu

F. M. Naderi

Michael H. Freilich

Follow this and additional works at: https://scholarsarchive.byu.edu/facpub

Part of the Electrical and Computer Engineering Commons

\section{Original Publication Citation}

Naderi, F. M., M. H. Freilich, and D. G. Long. "Spaceborne Radar Measurement of Wind Velocity Over the Ocean-an Overview of the NSCAT Scatterometer System." Proceedings of the IEEE 79.6 (1991): 85-66

\section{BYU ScholarsArchive Citation}

Long, David G.; Naderi, F. M.; and Freilich, Michael H., "Spaceborne radar measurement of wind velocity over the ocean-an overview of the NSCAT scatterometer system" (1991). Faculty Publications. 720. https://scholarsarchive.byu.edu/facpub/720 accepted for inclusion in Faculty Publications by an authorized administrator of BYU ScholarsArchive. For more information, please contact ellen_amatangelo@byu.edu. 


\title{
Spaceborne Radar Measurement of Wind Velocity Over the Ocean-An Overview of the NSCAT Scatterometer System
}

\author{
F. M. NADERI, SENIOR MEMBER, IEEE, M. H. FREILICH, AND D. G. LONG, MEMBER, IEEE
}

Invited Paper

\begin{abstract}
Satellite scatterometers are microwave radars capable of measuring near-surface vector winds (both speed and direction) over the oceans under all-weather conditions. Such data are required for most studies of upper ocean circulation, tropospheric dynamics, and air-sea interaction. In conjunction with an empirically determined relationship between radar cross section and wind velocity, scatterometry employs colocated measurements of the radar cross section of the ocean from multiple azimuth angles to estimate vector winds. The technique has been demonstrated with the flight of the Seasat scatterometer in 1978; additional satellite scatterometers will be orbited in the early 1990's by European and U.S. space agencies. This paper summarizes scatterometry and scatterometer design issues, with emphasis on the design of the NASA Scatterometer (NSCAT) to be flown on the Japanese ADEOS mission. Building on the Seasat experience, the NSCAT system includes several enhancements (such as three antenna azimuths in each of two swaths, and an on-board digital Doppler processor to allow backscatter measurements to be colocated everywhere within the orbit) that will greatly increase the quality of the NSCAT wind data.
\end{abstract}

\section{INTRODUCTION}

Satellite scatterometers are microwave radar instruments designed specifically to measure near-surface wind velocity over the global oceans under all-weather conditions [21] Wind stress is the single largest source of momentum to the upper ocean, and winds drive oceanic motions on scales ranging from surface waves to basin-wide current systems. Winds over the ocean also modulate air-sea fluxes of heat, moisture, gases, and particulates, thus regulating the crucial coupling between atmosphere and ocean that establishes and maintains global and regional climate. Finally, measurements of surface wind velocity can be

\footnotetext{
Manuscript received December 13, 1991; revised February 20, 1991. This work was performed at the Jet Propulsion Laboratory, California Institute of Technology, Pasadena, CA, under Contract with the National Aeronautics and Space Administration.

The authors are with the Jet Propulsion Laboratory, California Institute of Technology, Pasadena, CA 91109.
}

IEEE Log Number 9100191. assimilated into regional and global numerical weather models, thereby extending and improving our ability to predict future weather patterns on many scales [1].

Although measurements of ocean surface wind velocity (both speed and direction) are of critical importance in many geophysical studies, presently available data sets are deficient in coverage and/or accuracy. Most ocean ship reports are geographically and phenomenologically biased (since for safety and economic reasons ships avoid active storm regions). Ship reports of wind velocity are also notoriously inaccurate owing to untrained observers, poor instrumentation, badly placed anemometers, contamination owing to ship motion, and data transcription and transmission errors [24]. While measurements from moored meteorological buoys are considered highly accurate they are few in number and are concentrated in coastal regions in the northern hemisphere. Only satellite-borne instruments can acquire wind data with global coverage, high spatial resolution, and frequent sampling. Both satellite altimeters and multichannel microwave radiometers can be used to estimate all-weather wind speed; however, these instruments do not measure wind direction, and thus cannot be used to calculate air-sea momentum fluxes (inherently vector quantities) nor directly to gain increased understanding of atmospheric dynamics.

Satellite-borne scatterometers can acquire hundreds of times more observations of surface wind velocity each day than can ships and bouys. In addition, the accuracies of scatterometer measurements are nearly independent of conditions and location, and the measurements are globally distributed rather than being geographically and phenomenologically biased. Scatterometers are the only remote sensing systems able to provide accurate, frequent, high-resolution measurements of ocean surface wind speed and direction in both clear-sky and cloudy conditions. As such, they will play an increasingly important role in

0018-9219/91/0600-0850\$01.00 두 1991 IEEE 


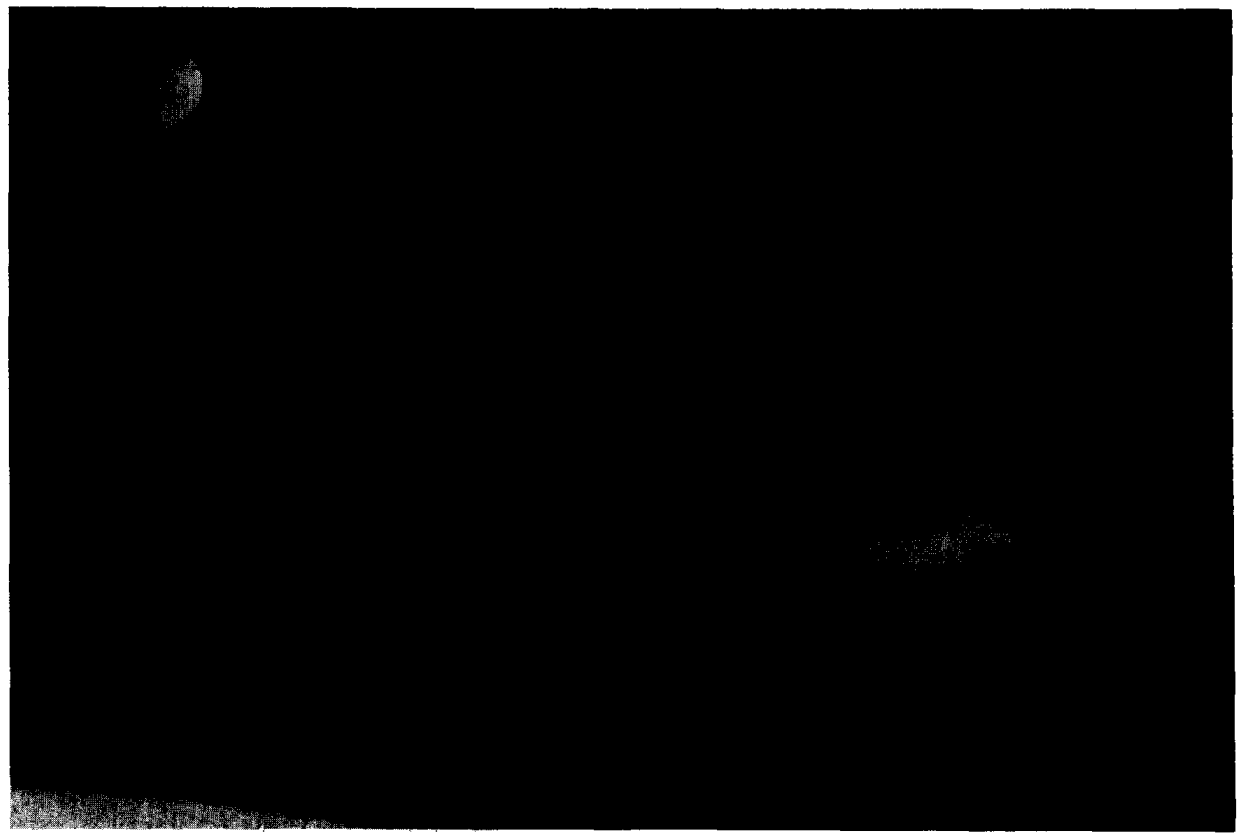

Fig. 1. On-orbit configuration of the ADEOS spacecraft. The NSCAT electronics boxes and antennas are mounted on the tower-like structure near the solar array mounting.

oceanographic, meteorological, and climate studies during the 1990's and beyond.

The temporal scales of important motions in the atmosphere and the ocean range from seconds to decades, and spatial scales range from meters to tens of thousands of kilometers [8]. Given the wide range of geophysical studies requiring surface wind velocity data, construction of a unified, consistent, achievable set of requirements for a satellite instrument is difficult. Following the successful flight of the Seasat scatterometer (SASS) in 1978 [10], [13], [15], NASA established the interdisciplinary Satellite Surface Stress Working Group to define the scientific requirements for the next NASA spaceborne scatterometer system [23]. As understanding of both science issues and scatterometer capabilities grew during the 1980 's, the Working Group report evolved into specific mission requirements, listed in Table 1. In short, the system must measure winds between 3 and $30 \mathrm{~m} / \mathrm{s}$ with an accuracy better than (the greater of) $2 \mathrm{~m} / \mathrm{s}$ or $10 \%$ in speed and $20^{\circ}$ in direction with a spatial resolution of $50 \mathrm{~km}$; virtually the entire oceans must be covered at least once every two days; geophysically useful products must be produced within weeks after data are acquired; and the instrument must be designed to acquire data for at least three years in order to allow investigation of annual and interannual variability.

This paper provides a general overview of important concepts in scatterometry and scatterometer design. In doing so, the NASA Scatterometer (NSCAT) is used as an example to illustrate a particular implementation. The
Table 1 Major NSCAT Technical Mission Requirements

\begin{tabular}{lcl}
\hline Wind speed & $2 \mathrm{~m} / \mathrm{s}$ (rms) & $3-20 \mathrm{~m} / \mathrm{s}$ \\
& $10 \%$ & $20-30 \mathrm{~m} / \mathrm{s}$ \\
Wind direction & $20^{\circ}$ (rms) & $3-30 \mathrm{~m} / \mathrm{s}$ \\
& (closest ambiguity) & \\
Spatial resolution & $25 \mathrm{~km}$ & $\sigma_{0}$ cells \\
& $50 \mathrm{~km}$ & Wind cells \\
Location accuracy & $25 \mathrm{~km}(\mathrm{rms})$ & Absolute \\
Coverage & $10 \mathrm{~km}$ (rms) & Relative \\
& $90 \%$ Ice-free ocean & \\
Mission duration & Every 2 days & \\
\hline
\end{tabular}

NSCAT instrument is planned for flight aboard the National Space Development Agency of Japan's ADvanced Earth Observing Satellite (ADEOS) scheduled for launch in early 1995. In addition to NSCAT, the ADEOS payload includes a wide-swath ocean color and temperature scanner (OCTS); a narrow-swath high-resolution advanced visible and near infrared radiometer (AVNIR); a U.S. supplied total ozone mapping spectrometer (TOMS); the French POLDIR instrument for measuring the polarization and directionality of the Earth's reflectances; an interferometric monitor for greenhouse gases (IMG); an improved limb atmospheric sounder (ILAS); and a retroreflector in space (RIS). The on-orbit configuration of the ADEOS spacecraft is shown in Fig. 1.

In Section II the principles of scatterometry are described with emphasis on the geophysical model relating backscatter to vector winds. Section III introduces key 
design concepts, including the antenna system and accuracy metrics required for end-to-end design tradeoffs. Although based heavily on the Seasat SASS design, the NSCAT flight instrument contains several enhancements resulting in increased measurement accuracy. The NSCAT flight hardware is briefly described in Section IV, while Section V presents in more detail the design of the critical onboard digital processor. Section VI outlines the ground processing needed to extract wind products from the NSCAT backscatter measurements, and the paper concludes with a survey of future planned scatterometer systems.

\section{PRinCiPles of SCATterometry}

Spaceborne scatterometers transmit microwave pulses to the ocean surface and measure the backscattered power received at the instrument. Since the atmospheric motions themselves do not substantially affect the radiation emitted and received by the radar, scatterometers use a highly indirect technique to measure wind velocity over the ocean. Wind stress over the ocean generates waves which roughen the sea surface. Changes in wind velocity cause changes in surface roughness, which in turn modify the radar cross section of the ocean and hence the magnitude of backscattered power. Scatterometers measure this backscattered power, allowing estimation of the normalized radar cross section $\left(\sigma_{0}\right)$ of the sea surface. In order to extract wind velocity from these measurements, the relationship between radar cross section and near-surface winds must be known.

The radar cross section $\sigma_{0}$ is calculated using the basic radar equation:

$$
\sigma_{0}=\frac{(4 \pi)^{3} R^{4} L P_{s}}{P_{t} G^{2} \lambda^{2} A}
$$

where $R$ is the slant range to the surface, $P_{t}$ is the transmitted power, $P_{s}$ is the received backscattered power, $L$ represents known system losses, $G$ is antenna gain, $A$ is the effective illuminated area, and $\lambda$ is the wavelength of the transmitted radiation.

From each illuminated location on the earth, the total received power is the sum of the backscattered power $P_{s}$ and a contribution $P_{n}$ resulting from instrument noise and the natural emissivity (at that frequency) from the earthatmosphere system. In order to determine $P_{s}$ accurately, the noise power $P_{n}$ must be estimated and subtracted from the total received power $P_{(s+n)}$; the radar equation can then be used to calculate $\sigma_{0}$.

\section{A. Geophysical Model Function}

The relationship between $\sigma_{0}$ and near-surface wind velocity is known as the "geophysical model function" and has been the subject of intense study over the last two decades. The model function should, in principle, be derivable from theory alone. However, such a task requires complete understanding of both the relationship between the wind and the sea surface geometry (on scales from millimeters to hundreds of meters), and the interaction between electromagnetic radiation and the sea surface. While significant

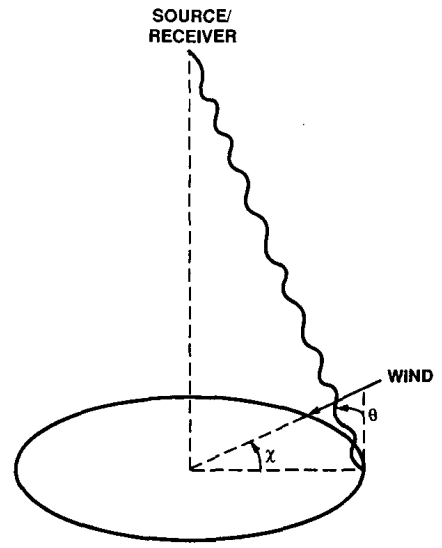

Fig. 2. Definitional sketch of the scattering geometry. Incidence angle $\theta$ is measured in the plane normal to the mean ocean surface Azimuth angle $\chi$ is the angle (in the plane of the mean surface) between the wind vector and the projection of the radar illumination vector.

progress in these areas has been made, the gaps in our knowledge remain formidable [6], [35].

Lacking rigorous theoretically based expressions, empirical models have been established to relate ocean radar cross section and the near-surface wind. With the flight of the first spaceborne scatterometer on Seasat in 1978, several million calibrated $\sigma_{0}$ measurements became available for use in model function refinement studies, along with several thousand high quality in situ meteorological and oceanographic measurements spanning a range of atmospheric and oceanic conditions. Wentz and coworkers [33], [34] have used the full Seasat data set to derive a Ku-band model function ("SASS-2"); the Seasat data reprocessed using this model is the most consistent, highest quality spaceborne scatterometer data set available.

The basic features of the scatterometer model function are summarized below, with emphasis on the constraints that they place on the design of spaceborne scatterometer systems.

The geophysical model function can be written most generally as

$$
\sigma_{0}=f(|U|, \chi, \cdots ; \theta, f, \mathrm{pol})
$$

where $|U|$ is wind speed, $\chi$ is the azimuth angle between the incident radiation and the wind vector (see Fig. 2), .. represents the (small) effects of non-wind variables such as long waves, stratification, temperature, etc., $\theta$ is the incidence angle measured in the vertical plane (Fig. 2), and $f$ and pol are the frequency and polarization, respectively, of the incident radiation.

Figures 3 and 4 represent schematically the model function for Ku-band v-pol based on Seasat scatterometer data. Figure 3 shows dependence of $\sigma_{0}$ on wind speed as a function of incidence angle $\theta$ for a given azimuth angle $\chi$. In the incidence angle range between $20^{\circ}$ and $65^{\circ}$, backscattered radiation results principally from resonant 


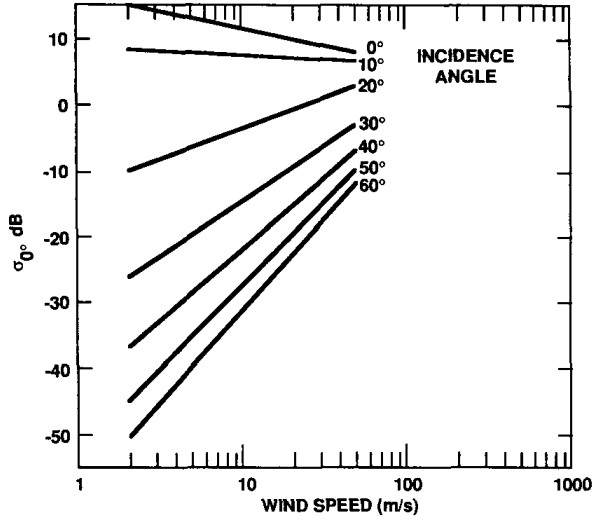

Fig. 3. Normalized radar cross section (v-pol radiation, crosswind azimuth angle) as a function of wind speed for incidence angles between $0^{\circ}$ and $60^{\circ}$.

Bragg scattering from short ocean waves having wavelengths comparable to that of the incident electromagnetic radiation (approximately $2 \mathrm{~cm}$ at $\mathrm{Ku}$-band) [27], although non-Bragg scattering from longer ocean waves cannot be neglected (cf. [5], [9], [12]).

Empirical studies have also demonstrated that at these incidence angles $\sigma_{0}$ is a sensitive function of wind direction as measured relative to the radar azimuth angle $\chi$ ([14], [28], and many others). Figure 4 shows that the relationship between $\sigma_{0}$ and $\chi$ is nearly $\cos (2 \chi)$, with $\sigma_{0}$ having maxima at upwind $\left(\chi=0^{\circ}\right)$ and downwind $\left(\chi=180^{\circ}\right)$, and minima near crosswind $\left(\chi=90^{\circ}\right.$ and $\left.270^{\circ}\right)$. This detectable upwind-crosswind modulation of $\sigma_{0}$ forms the basis for the measurement of wind direction by scatterometers. The modulation amplitude increases with increasing incidence angle, is typically larger for h-pol than for v-pol radiation, and is (relatively) largest at low wind speeds.

Although difficult to detect in Fig. 4, there is also a small but significant difference in $\sigma_{0}$ between upwind and down- wind angles (known as the "upwind-downwind asymmetry"), with upwind cross sections being typically larger than downwind (see, e.g., [33], [34]). The upwind-downwind asymmetry increases with increasing incidence angle, is larger for h-pol than for v-pol radiation, and is larger at lower wind speeds. Although small, this asymmetry is critical; in its absence, scatterometer vector wind measurements would always result in a $180^{\circ}$ ambiguity in direction (i.e., it would not be possible to determine whether the wind was blowing "from" or "to" a given direction). Because of the existence of this asymmetry, it is possible, in principle, to determine a unique wind vector, although the small magnitude of the asymmetry requires that accurate measurements of backscatter cross section be obtained.

\section{B. Need for Multiple Measurements}

Estimation of wind velocity from a $\sigma_{0}$ measurement involves inversion of the model function given by (2). However, for a single $\sigma_{0}$ measurement, no unique solution exists; a single scalar measurement (such as $\sigma_{0}$ ) is insufficient to solve for both wind speed and wind direction, as shown in Fig. 5. The heavy solid line in this figure represents all possible vector winds (i.e., pairs of wind speed $|U|$ and wind direction $\gamma$ ) that are consistent with a given single noise-free $\sigma_{0}$ measurement. If a second measurement of $\sigma_{0}$ is obtained from the same region of the sea surface but from an antenna oriented $90^{\circ}$ with respect to the first, the dashed curve in Fig. 5 results. Since each curve represents all possible $(|U|, \gamma)$ values corresponding to the $\sigma_{0}$ measurement, the solution consistent with both measurements must be one of the (up to 4 ) intersections identified by arrows in Figure 5 .

This fourfold ambiguity in wind direction resulting from $\sigma_{0}$ measurements at only two (orthogonal) azimuth angles severely detracted from the utility of the Seasat scatterometer data. Significant and time-consuming ground-based processing using auxiliary meteorological information was required to select the correct wind direction from the possible solutions (see also Section VI-C). However, addi-

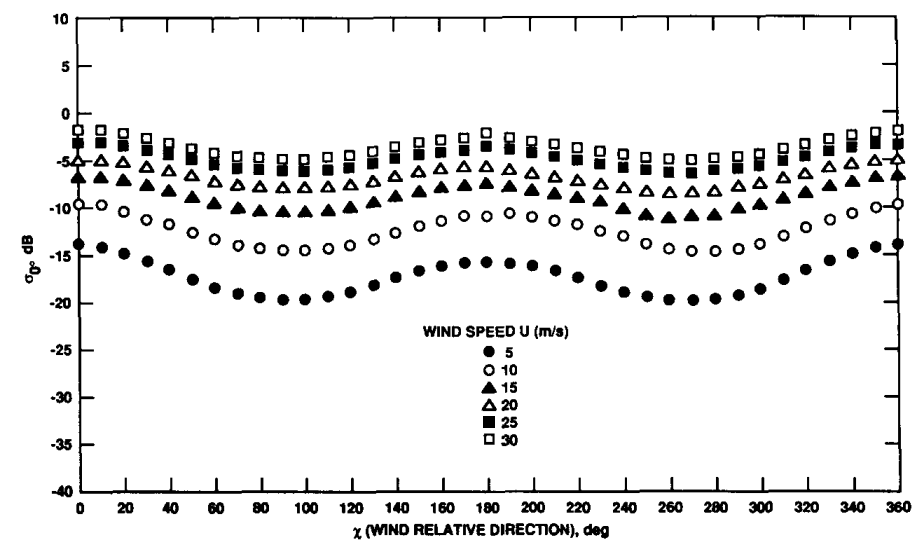

Fig. 4. Normalized radar cross section as a function of azimuth angle (h-pol, $\theta=30^{\circ}$ ) for several wind speeds. 


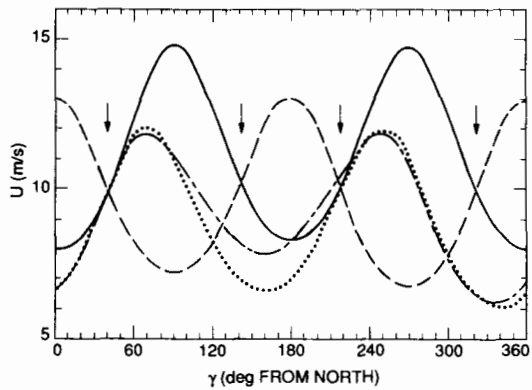

Fig. 5. Loci of possible vector winds associated with colocated noise-free $\sigma_{0}$ measurements obtained from antennas at various azimuth angles. Heavy solid line: antenna angle of $0^{\circ}$ ( $v$-pol) dashed line: angle of $90^{\circ}$ (v-pol); light solid line: angle of $25^{\circ}$ (v-pol); dotted line: angle of $25^{\circ}$ (h-pol). Arrows indicate solutions obtained using only the antennas at $0^{\circ}$ and $90^{\circ}$.

tional $\sigma_{0}$ values obtained from antennas at yet other angles and/or using different polarizations yield additional possible solution loci illustrated by the dotted and light-solid curves in Fig. 5. In this case of noise-free measurements, the additional measurements allow a single intersection of all four curves to be identified, e.g., [14], [20], [26], [31]. In practice, even with several $\sigma_{0}$ measurements, the model function inversion results in multiple solutions (corresponding to "near intersections" of all four curves) having nearly the same speed but differing widely in direction. These multiple solutions (historically known as "ambiguous vectors") result from a combination of instrumental noise, geophysical noise, and the small upwind-downwind asymmetry of the model function. Typically, the solution loci intersect relatively closely near two values of $\gamma$ separated by approximately $180^{\circ}$ (corresponding to the small upwinddownwind asymmetry). While additional processing is still required to select a unique wind direction, the magnitude and complexity of the task is greatly reduced over that required for the fourfold case of SASS. Planned future scatterometers all will have the capability of acquiring $\sigma_{0}$ data from three or more azimuth angles within the primary measurement swaths.

\section{SCATTEROMETER SySTEM DESIGN}

As discussed in Section II, estimation of wind velocity from scatterometers requires multiple colocated measurements of backscatter from different azimuth angles. In addition, to realize frequent global coverage, a wide observation swath must be imaged during each satellite orbit. The antenna concept dictates the swath width as well as the number and geometry (azimuth and incidence angles) of the $\sigma_{0}$ measurements. The antenna concept also severely constrains the means by which spatial resolution is achieved. The choice of antenna subsystem concept is thus the most fundamental issue in scatterometer design.

\section{A. Concepts for Antenna Subsystems}

Although the dual objectives of multiple azimuth viewing and wide swath coverage can be met using either multiple fan beam antennas or scanning spot beams, the Seasat SASS and U.S. and European scatterometers planned for flight in the next five years rely on multiple fan beam illumination. A conceptual design using fan beam antennas is illustrated in Fig. 6, with each antenna producing an instantaneous footprint which is several hundred kilometers long but only a few kilometers wide. Two sets of three antennas are used, each set illuminating a wide swath on one side of the subsatellite track. The antennas on each side are arranged at three different azimuth angles. As the satellite orbits, a resolution element on the surface of the ocean is observed first by the forward looking antenna, a short time later by the center antenna, and finally by the aft antenna. This produces three colocated, nearly simultaneous observations from three different azimuth angles.

Although conceptually simple, the fan beam design introduces several complexities in practice: the incidence angle $\theta$ varies as a function of cross-swath (along-beam) position, and thus the geophysical model function must be known for a wide range of incidence angles; for $\theta<20^{\circ}, \sigma_{0}$ is only weakly sensitive to wind speed and virtually insensitive to wind direction, resulting in a gap centered on the satellite subtrack within which vector winds cannot be calculated; and received power $P_{s}$ decreases dramatically across the swath (even for fixed $\sigma_{0}$ ) owing to the $R^{4} / A$ term in the radar equation (1), thus requiring larger antenna gain in the far swath to offset the longer range. On the other hand, as discussed in Section II, $\sigma_{0}$ (and hence $P_{s}$ ) sensitivity to wind speed and direction is smaller at incidence angles in the near swath, and thus must be measured with greater relative accuracy. Therefore, orientation of the peak antenna gain requires a compromise to satisfy both near and far swath requirements.

Figure 7 shows the footprint for the NSCAT fan beam antenna subsystem. A set of four antenna beams illuminate each side of the subsatellite track. On the right-hand side, antenna 1 has a $45^{\circ}$ azimuth angle and transmits v-pol, antenna 2 (which transmits both v- and h-pols) has a $65^{\circ}$ azimuth angle producing coregistered beams, and antenna 3 , also transmitting v-pol, has an azimuth angle of $135^{\circ}$. For each orbit, these antennas sweep a $600-\mathrm{km}$ wide swath (on each side) which is further resolved into smaller observation cells by means of timing and Doppler filtering as discussed below.

\section{B. Resolution}

Since fan-beam systems illuminate large, elongated areas on the surface simultaneously, methods must be devised to resolve the received power from each antenna beam as a function of spatial location. In addition, the antennas must be illuminated in such a way as to ensure colocated $\sigma_{0}$ measurements from each beam with $25-\mathrm{km}$ spatial resolution on an earth-located grid. As described below, different techniques are used to achieve along-beam and along-track resolution.

Along-Beam Resolution: Although either Doppler filtering or time gating can be used to obtain along-beam resolution, Doppler filtering was used in Seasat scatterometer and is 


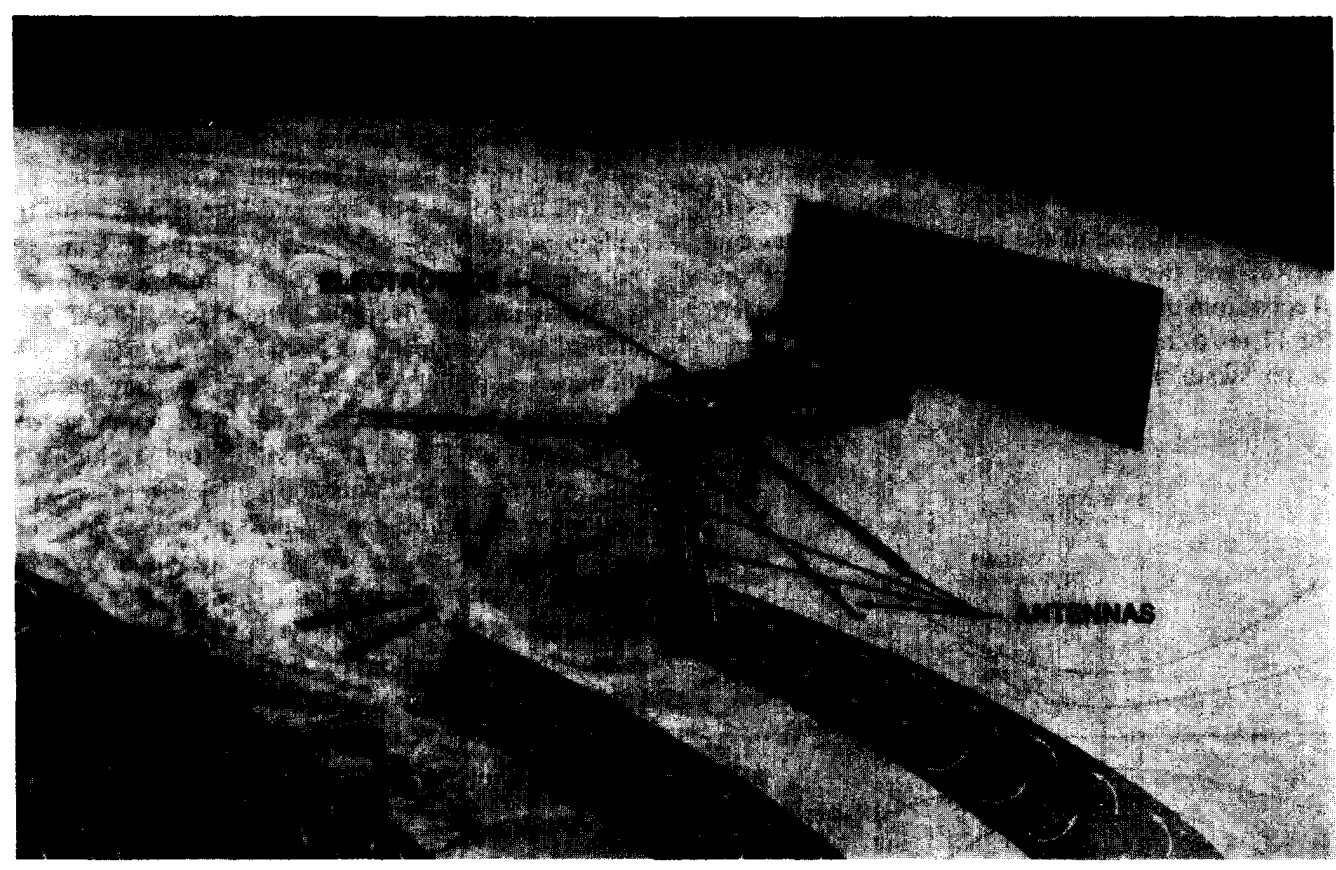

Fig. 6. Conceptual drawing of a spaceborne scatterometer, its antenna footprints on the ocean surface and its coverage swaths.

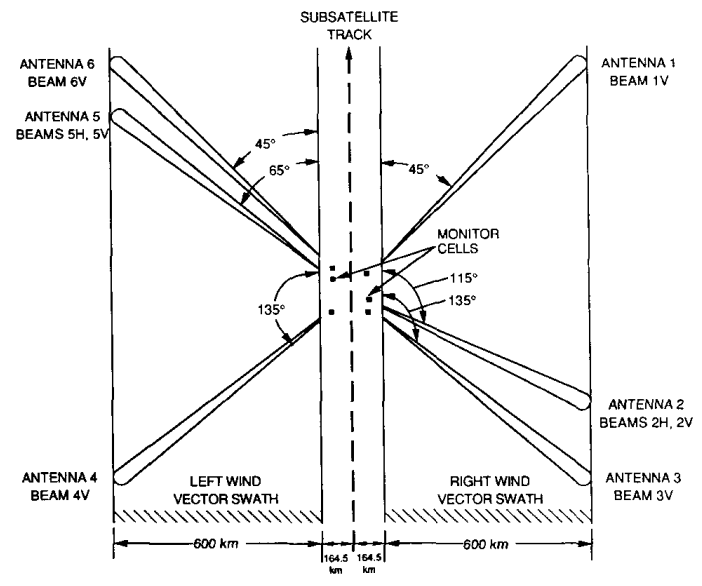

Fig. 7. NSCAT antenna illumination patterns on the ocean surface.

planned for NSCAT. The technique makes use of the fact that the radar echo reflected from the ocean surface is Doppler shifted due to motion of the spacecraft relative to the earth's surface. The return echos from different portions of the antenna footprint have different Doppler shifts, with a larger shift at far swath and a smaller shift at near swath. This difference in Doppler shift can be exploited to filter the returned echo into cross-track (along-beam) resolution elements or "cells". Figure 8 illustrates the iso-Doppler lines (lines representing loci of all points on the ocean having the same Doppler shift relative to the spacecraft) superimposed on the antenna pattern footprints. Note that the iso-Doppler lines are closely spaced in the near swath and spread out in the far swath. For NSCAT, a $25-\mathrm{km}$ resolution cell in the near swath is bounded by Doppler lines approximately $15 \mathrm{kHz}$ apart while the last $25-\mathrm{km}$ resolution cell in the far swath has a Doppler bandwidth of only $2 \mathrm{kHz}$. By processing the returned signal with a number of bandpass filters of unequal bandwidth, NSCAT can resolve the $600-\mathrm{km}$ wide swath on each side of its subsatellite track into 24 " $\sigma_{0}$ cells" each having $25-\mathrm{km}$ spatial resolution.

Along-Track Resolution: Measurement timing is used to achieve along-track resolution such that the centers of cells measured by each antenna beam are approximately colocated with a spatial resolution of $25 \mathrm{~km}$. ADEOS, the NSCAT host spacecraft, will fly in a 795-km 101-min polar orbit resulting in a subsatellite velocity of approximately $6.7 \mathrm{~km} / \mathrm{s}$. The desired $25-\mathrm{km}$ resolution is achieved by making measurements at each azimuth angle once every $3.74 \mathrm{~s}$, the time that it takes for the subsatellite point to have moved $25 \mathrm{~km}$. Since a single transmitter/receiver is time-shared among the eight antenna beams, during each 3.74-s measurement cycle, $0.468 \mathrm{~s}$ are allocated for each antenna beam to make $\sigma_{0}$ measurements.

\section{Signal Structure and $\sigma_{0}$ Measurement Accuracy}

As discussed above, the NSCAT transmitter/receiver must sequence through all eight antenna beams within $3.74 \mathrm{~s}$ in 
order to achieve a $25-\mathrm{km}$ along-track resolution, resulting in a maximum dwell time of $468 \mathrm{~ms}$ within each of the eight antenna footprints. The round trip propagation times of radar pulses from the NSCAT orbital altitude to the near and far swaths are approximately 5 and $11 \mathrm{~ms}$, respectively. Each transmitted pulse must thus be limited to $5 \mathrm{~ms}$ in duration so that at the end of the pulse the transmitter can be turned off and the receiver can begin to measure the returned echo from the near swath. The receiver must be left active for $11 \mathrm{~ms}$ to ensure collection of all returned power from the far swath, resulting in a 16-ms transmit/receive cycle.

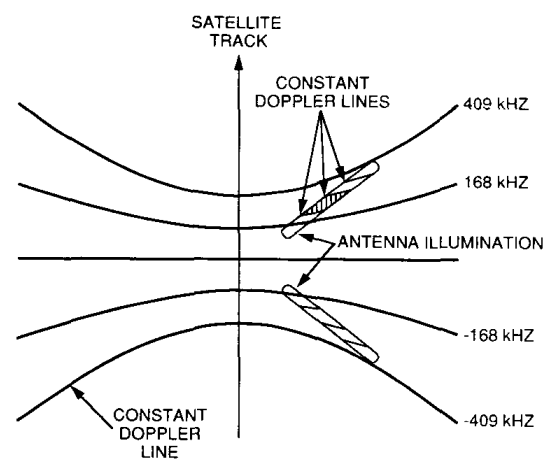

Fig. 8. The overlay of the scatterometer fan beams on constant Doppler lines. The intersection of these lines with the beams' footprints define Doppler cells within which wind vectors are measured.

As many as 29 transmit/receive cycles can thus take place within each 468-ms dwell period (see Fig. 9), with the returned power (dispersed in both time and Doppler frequency) integrated across the pulse cycles. However, as discussed in Section II, the received power is composed of both actual backscattered radiation and instrument and geophysical noise (not related to the transmitted pulse). An estimate of the noise power must thus be obtained during each beam dwell period before calculation of $\sigma_{0}$. For NSCAT, the design was optimized so that 25 transmit/receive and 4 receive-only noise measurement cycles are included in each beam dwell period. (To simplify the design, each receive-only noise measurement cycle is composed of $5 \mathrm{~ms}$ during which no pulse is actually transmitted followed by the usual $11 \mathrm{~ms}$ receiving period.)

Wind velocity accuracy depends critically on the accuracy of the $\sigma_{0}$ measurements. A commonly adopted metric for evaluating the $\sigma_{0}$ measurement accuracy is " $K_{P}$ " defined as the normalized standard deviation of the $\sigma_{0}$ measurement. A general goal in scatterometer design is to minimize $K_{P}$ [32]. For a fan beam scatterometer employing digital Doppler filtering, $K_{P}$ may be approximated as [18], see also, [7]

$$
K_{P}=\frac{\left(1+2 / S+1 / S^{2}\right)}{\sqrt{\left(N_{p} T_{p} B_{c}\right)}}
$$

where $N_{p}$ is the number of transmit pulses accumulated into one $\sigma_{0}$ measurement, $T_{p}$ is the transmit pulselength, $B_{c}$ is the $\sigma_{0}$ cell bandwidth and $S$ is the measurement signal-to-noise ratio (which depends on $\sigma_{0}$ ). $K_{P}$, coupled with end-to-end system simulation, can be used to make design tradeoffs. For example, the number of transmit pulses versus noise-only measurements and the transmit pulselength were selected so as to minimize $K_{P}$.

The signal time/Doppler history for NSCAT is shown in Fig. 10. A signal processor aboard NSCAT processes the received signal following each 5 -ms transmitted pulse. The signal is bandpass filtered (with appropriate center frequencies and Doppler bandwidths; see Section IV below) to measure the signal plus noise power from each $(25-\mathrm{km})$ resolution cell within the swath. The echoes returned from each of the 25 transmitted pulses are similarly processed and the results accumulated. The four noise-only measurements are also similarly processed. During ground processing, subtraction of the noise-only measurements from the signal plus noise measurements yields an estimate of the received signal power $\left(P_{s}\right)$ which is used in (1) to calculate $\sigma_{0}$ for each $25 \mathrm{~km}$ cell.

\section{HARDWARE DESIGN, IMPLEMENTATION, AND CALIBRATION}

This section provides a brief description of the NSCAT flight instrument as an example of how the design concepts discussed in the previous section can be implemented. The system-level design of the NSCAT flight instrument is based heavily on the SASS design. However, significant improvements to the design have been made along the lines first suggested and examined by [11]. These include using an on-board digital Doppler processor in place of the analog processing employed by SASS, an advanced lownoise amplifier, and addition of a third antenna azimuth. The NSCAT instrument consists of three major subsystems as illustrated in Fig. 11: the Radio Frequency Subsystem (RFS), the antenna subsystem, and the Digital Data Subsystem (DSS). The design and operation of each of these subsystems is described in the following subsections.

\section{A. RFS}

The basic function of the RFS is to generate the transmitted pulses and route them to the antenna subsystem through a switch matrix; to receive the returned signal, down-convert and pass the signal to the DSS; and to provide a noise source for on-board calibration of the instrument. A functional block diagram of the RFS is shown in Fig. 12. Transmit pulses are generated by gating and amplifying a continuous tone at $13.995 \mathrm{GHz}$. The transmitted pulses are routed to each antenna beam in sequence by a circulator switch matrix. A five-stage GaAsFET, low noise amplifier (LNA) with a noise figure of $3 \mathrm{~dB}$ is used to amplify the return echo. Within the RFS, the received signal is split into 4 channels, down-converted to baseband, and routed to the DSS

PROCEEDINGS OF THE IEEE, VOL. 79, NO. 6, JUNE 199 


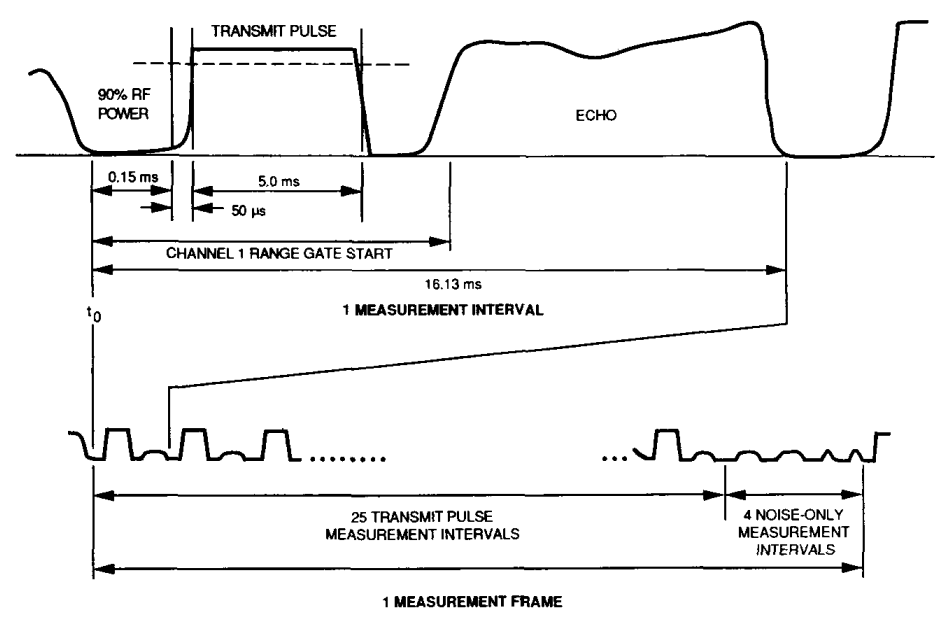

Fig. 9. The signalling scheme for NSCAT. A 5-ms transmit pulse is followed by an approximately 11-ms period for reception of the returned echo.

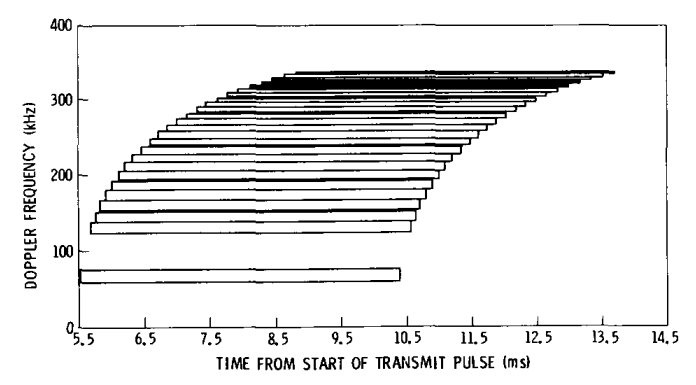

Fig. 10. A typical Doppler history for the radar echo return from a forward-looking antenna. Each boxed region indicates the time-bandwidth region for a given measurement cell.

A temperature-compensated stable local oscillator (STALO) at $49.98 \mathrm{MHz}$ and two LO's at 249.91 and 946.66 $\mathrm{MHz}$ are used to generate the $13.995-\mathrm{GHz}$ transmit frequency. The transmitted signal is interrupted continuous wave (CW) with approximately 5-ms pulses and a pulse repetition frequency (PRF) of approximately $62 \mathrm{~Hz}$. Gating control for the transmit signal is provided by the DSS.

The transmit signal is amplified by a high voltage ( $-8.5 \mathrm{kV}$ cathode) traveling wave tube amplifier (TWTA) consisting of a coupled-cavity, gated grid traveling wave tube (TWT) and an associated high voltage power supply. The TWT's have a four-stage collector for high efficiency $(43 \%)$ at $120-\mathrm{W}$ peak output power. The DSS provides a pulse to switch the grid voltage synchronous with the input signal gating. For redundancy in case of tube or power supply failure, two independent TWTA's are included in the RFS although only one is operated at a time.

The RFS frequency plan is complicated by the need for different LO frequencies for each antenna beam and for the four DSS output channels (discussed below in Section
IV-C). In the receive path, a high-side LO of $14.245 \mathrm{GHz}$ is used in conjunction with a band reject filter to prevent interference from possible emissions from other instruments at $13.6 \mathrm{GHz}$ (the frequency used commonly by satellite radar altimeters). The first $L O$ in the receiver path is at $250 \mathrm{MHz}$ after high-side mixing of the receive signal.

The second LO frequency, chosen from one of four possible values (two each approximately $250 \pm 17 \mathrm{MHz}$ ), is generated by a phase-locked loop and digital divider with a modulo selected by the DSS. The frequency chosen is a function of the antenna number. For aft-facing antennas, the Doppler shift is opposite in sign from the forward-facing antennas though of the same bandwidth. The second RFS mixing frequency is, therefore, selected for either highside or low-side mixing such that the Doppler shifts are all converted to positive, thus simplifying the design of the DSS. Separate frequencies are additionally required for antennas at $\left|45^{\circ}\right|$ and $\left|135^{\circ}\right|$ (i.e., antennas $1,3,4$, and 6) and for those at $\sim\left|65^{\circ}\right|$ (antennas 2 and 5). The resulting $17-\mathrm{MHz}$ RF signal is then split into four channels and filtered by multistage narrow-band crystal filters. Four crystal oscillators provide four closely spaced LO frequencies used to mix each channel to baseband. Each channel output is lowpass filtered and passed to the DSS.

Physically, the RFS consists of two separately packaged assemblies, the radio electronics unit (REU) and the RFS interface unit (RIU). The REU is the largest at 36.5 " $\times 32$ " $\times$ 10 " and contains most of the RFS hardware. The RIU contains power conditioning and switching circuitry and is housed in a $11 " \times 14$ " $\times 10$ " enclosure. The total RFS mass (including structure and cabling) is $108.5 \mathrm{~kg}$ and the power is $152.9 \mathrm{~W}$.

The electronics in both the RFS and DSS are mounted on machined aluminum baseplates which provide a thermal sink in order to maintain the electronics at a constant temperature. The baseplate radiates excess heat into space 


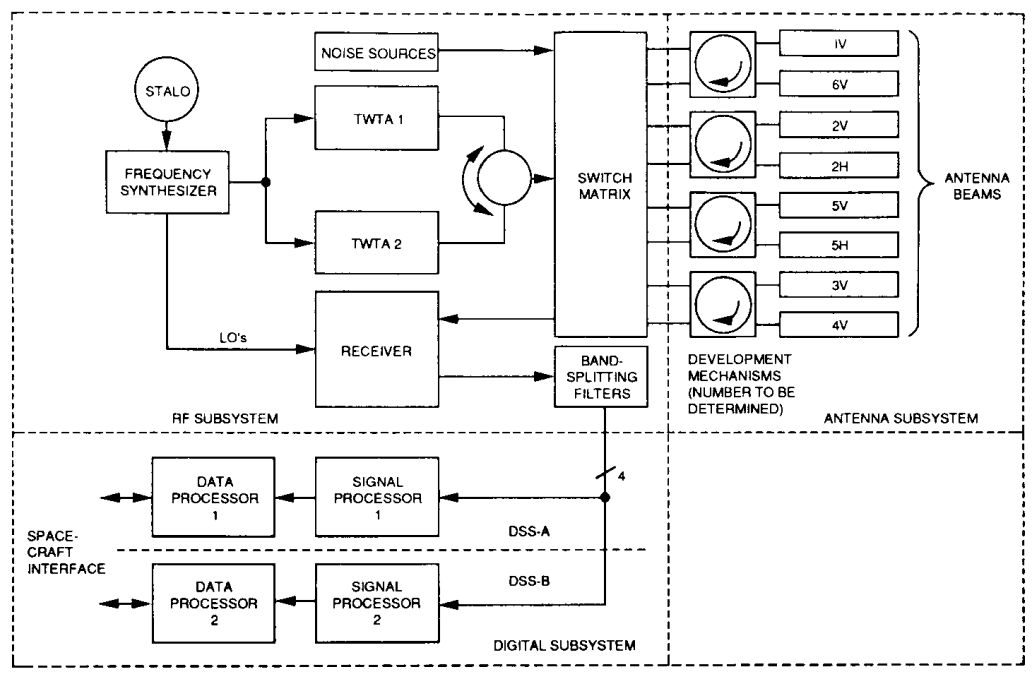

Fig. 11. A simplified block diagram of NSCAT.

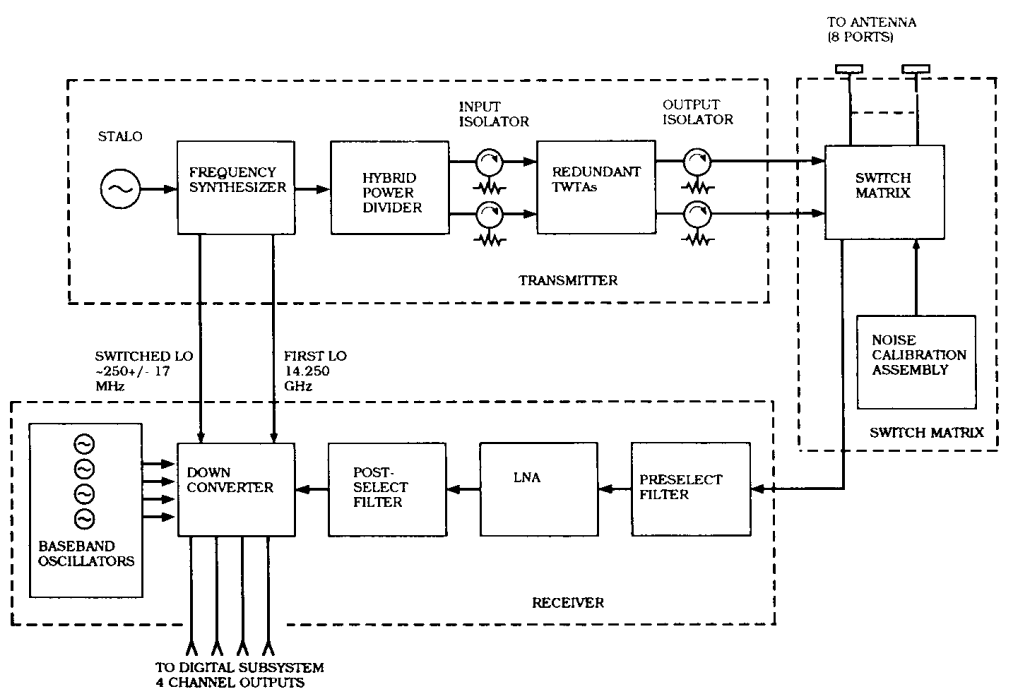

Fig. 12. A simplified block diagram of the NSCAT radio frequency subsystem (RFS).

from the backside. The top cover of the enclosures is mounted to the spacecraft structure with the sidewalls acting as standoffs.

In order to calibrate the receiver gain, a calibration noise source is included in the RFS. Periodically (once every $8 \mathrm{~min}$ ) the transmitter is disabled by command of the DSS and the calibration noise source is switched on and fed into the LNA. The noise source is an oven-mounted tunnel diode with an excess noise temperature of $20500 \mathrm{~K}$. The diode can be turned off to additionally provide an ambienttemperature calibration source. The noise source provides a very high stability constant power source which is used in the ground processing to compute the receive path gain. A power monitor is included in the transmit path to measure the transmitted power.

\section{B. Antenna Subsystem}

The NSCAT antenna subsystem consists of 6 identical, dual-pol fan beam antennas and associated deployment mechanisms. Each antenna is made up of two separate slotted-waveguide-array fed horns (one for v-pol and one for h-pol radiation) supported by a graphite-epoxy structural member. While all the antennas are dual-pol, only a single polarization is used for antennas $1,3,4$, and 5 (refer to Fig. 7).

PROCEEDINGS OF THE IEEE, VOL. 79, NO. 6, JUNE 1991 
To achieve the desired fan beam illumination pattern on the Earth's surface, the NSCAT antennas are long (approximately $10 \mathrm{ft}$ ) and thin (each horn is 2.5 " wide by $4-5$ " deep). The antennas are constructed of graphite-epoxy horns and thin-wall aluminum waveguides. Electrically, the antennas are slotted-waveguide-array fed horns each producing a fan beam with a $25^{\circ}$ beamwidth in elevation (along-beam) and a very narrow $0.4^{\circ}$ beamwidth in azimuth (cross-beam). From the orbit altitude of $795 \mathrm{~km}$, this results in a narrow and long instantaneous footprint which is $7-15 \mathrm{~km}$ wide and more than $900 \mathrm{~km}$ long. The antenna peak gain is $33.5 \mathrm{~dB}$ which is tilted towards the far swath to compensate for the longer range. The first sidelobes are -15 and $-20 \mathrm{~dB}$ in the wide and narrow beams, respectively.

The six antennas are stowed during launch. After launch, four single-axis, spring-loaded rotary-joint deployment mechanisms are used to deploy the antennas to their final positions. Pyrotechnic releases under control of the spacecraft are used to free the stowed antennas and initiate the deployment process. The antennas are mounted on short (8") booms attached to their feed ends and the deployment mechanisms. Waveguides run through the boom and deployment mechanism to couple the circulator in the RFS to each of the antenna horns. The total antenna mass, including waveguides but excluding the deployment mechanisms is $67.1 \mathrm{~kg}$.

The antennas are calibrated to within $0.25 \mathrm{~dB}$ before flight and have temperature sensors mounted along the antennas to allow dynamic changes in the on-orbit gain pattern due to thermal variation to be corrected in the ground processing. To achieve this high degree of calibration, a cylindrical near-field range was developed at JPL. The range consists of a rotary turntable upon which the antenna is vertically mounted, feed end down; a near-field probe which moves vertically on a track; and a network analyzer, all computer controlled and contained within an anechoic room. A vertical series of horizontal "slices" of the near-field radiation pattern are obtained and used to reconstruct the far-field antenna pattern. Through careful calibration of the near-field range equipment, the desired antenna calibration accuracy is achieved.

\section{DSS}

NSCAT will be the first spaceborne scatterometer to utilize on-board digital processing of the Doppler-shifted received signal. The NSCAT DSS consists of two processors: a command and control processor (CP) and a digital Doppler processor (DDP). The CP performs the nominal functions required to control the operations of the instrument. These include receiving commands from the spacecraft, collecting housekeeping data and formatting downlink telemetry. In addition, the $\mathrm{CP}$ also computes certain processing parameters for the Doppler processor (described later). The heart of the $\mathrm{CP}$ is a $80 \mathrm{C} 86$ microprocessor which controls the instrument state and operation. Software for the CP is stored in $64 \mathrm{~kb}$ of $\mathrm{ROM}$, with $32 \mathrm{~kb}$ of write-protected RAM used for the parameter tables and for temporary storage. The DSS is implemented primarily in TTL (although high-speed CMOS LSI is used for the microprocessors and memories) on custom circuit cards measuring approximately 16.3 " $\times 6.3$ ". Each card is composed of 12-layer printed wiring boards mounted on a honeycomb subchassis. Two cards each are packaged in a single tray. Two identical sets of cards are interleaved (for thermal reasons) in the trays, thus providing full redundancy for the DSS. The DSS mass and power are, respectively, $36.1 \mathrm{~kg}$ and $78.5 \mathrm{~W}$.

The primary objective of the onboard DDP is to achieve along-beam resolution (utilizing the spatially varying Doppler shift of the returned signal) and to allow accurate calculation of the backscattered and noise-only power by integrating multiple pulses for each along-beam cell. The DDP represents a significant advance over the Seasat scatterometer, and contributes greatly to the enhanced accuracy and utility of the NSCAT data. Because the earth rotates, the Doppler shift associated with any point in an antenna beam is a function of spacecraft latitude; thus $\sigma_{0}$ cell centers correspond to varying Doppler shifts with latitude, and cell boundaries likewise are associated with different Doppler frequencies at different point in the satellite's orbit. The SASS system used analog filters having fixed bandwidths and center frequencies, resulting in significant variations in the sizes and locations of $\sigma_{0}$ cells as the spacecraft orbited. These variations decreased the effective measurement swath width (since vector winds could be calculated from only those regions imaged by both the fore and aft antennas) and contributed to inaccurate wind velocity estimates for spatially varying wind fields (since cells from different antennas were not perfectly colocated). The NSCAT DDP not only allows more accurate measurements of $\sigma_{0}$, but also assures that $\sigma_{0}$ cells from different antenna beams are colocated and of comparable area. The DDP is described in detail in [18], and only a summary is presented here.

The signal processing performed in the DDP is depicted in Fig. 13. To simplify the design, four processing channels are used, each covering only part of the total $450 \mathrm{kHz}$ processing bandwidth. For each channel the DDP accepts baseband signal from the RFS, digitizes the signal, and measures the received power in each of the $\sigma_{0}$ cells. The estimates of the $\sigma_{0}$ cell powers are obtained by the following:

1) computing the FFT of the sampled input data;

2) applying a data window by convolution to minimize spectral leakage;

3) squaring (power detection) the windowed FFT output;

4) summing ("binning") the periodogram estimates over the range of frequency bins corresponding to each $\sigma_{0}$ cell bandwidth.

The binning accumulation of the periodogram (squared FFT output) bins (step 4) is performed over both the frequency bins and over measurement pulses ( 25 for signal power measurement and 4 for noise-only measurements). Power measurements for all cells are computed simultaneously, with time-overlapped FFT input segments used to 


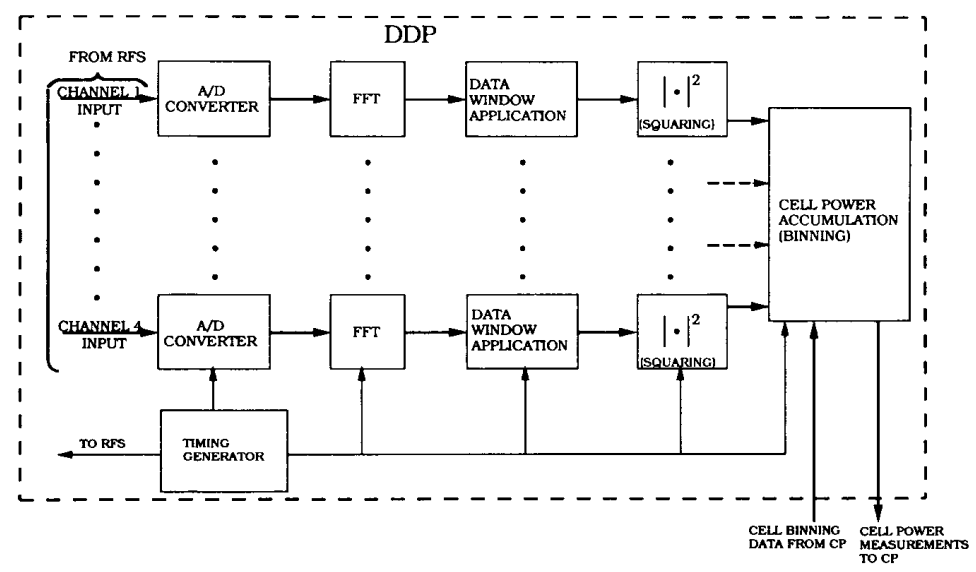

Fig. 13. A simplified block diagram of the digital Doppler processor.

minimize the adverse effects of the data windowing on the measurement $K_{P}$ [18].

The power measurement corresponding to each $\sigma_{0}$ cell is made by summing a specified range of periodogram bins from a given channel in the signal processor. Both the center frequencies and the bandwidths of the cells must therefore be known. Figure 14 shows that the center frequency of the $\sigma_{0}$ cells vary as the satellite goes around its orbit. The excessive on-board memory required to store the center frequencies for all beams and orbit locations (more than $6 \mathrm{Mb}$ for NSCAT) led to the decision to compute the cell center frequencies onboard the spacecraft. The expression relating the cell location to its Doppler shift as a function of the orbit is quite complex and generally unsuited for onboard computation. The onboard "binning algorithm" therefore uses an approximation to the exact expression which provides an excellent tradeoff between computational complexity and error. This approximation consists of the first 3 terms in the Fourier series expansion relating the $\sigma_{0}$ cell center frequency, $F_{c}$, to the time, $t$, from the ascending node (northbound equator crossing),

$$
F_{c}(t)=A_{0}+A_{1} \cos \left(P_{d} t+\phi_{1}\right)+A_{2} \cos \left(2 P_{d} t+\phi_{2}\right)
$$

where $A_{0}, A_{1}, A_{2}, \phi_{1}$, and $\phi_{2}$ are constants stored in the RAM and $P_{d}=2 \pi / P$ where $P$ is the orbit period. To maintain constant $\sigma_{0}$ cell crosstrack locations, these values may be updated by a ground command to accommodate changes in the spacecraft orbit. Storage of these constants requires approximately $7 \mathrm{~kb}$. For each $\sigma_{0}$ cell, the $\mathrm{CP}$ computes the cell center frequency using (4) and the channel in which this frequency falls. Then, the FFT bin numbers corresponding to the cell bandwidth are computed and transferred to the DDP. In the DDP these values are used to control the accumulation of the periodogram bins into the cell power measurements.

Since the center frequencies of the $\sigma_{0}$ cells change as a function of the orbit, the $\sigma_{0}$ cells may move from one of the four processing channels described above to another.

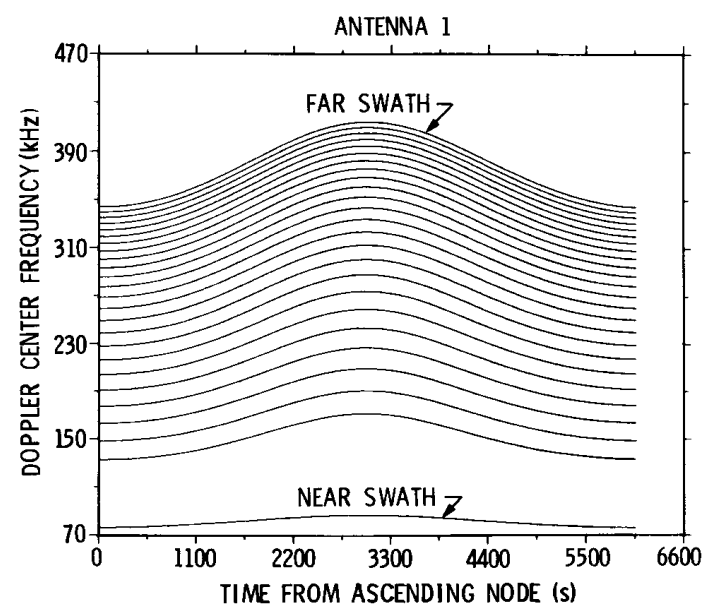

Fig. 14. Illustration of the shift in the center frequency of the $\sigma_{0}$ cells as a function of the time from the ascending node.

To accommodate this, the channel bandwidths overlap in frequency so that a given $\sigma_{0}$ cell bandwidth is always completely contained within a single channel regardless of its center frequency. This simplifies the DDP and eliminates the need to match channel gains precisely.

The use of multiple processing channels permits separate time gates on each of the channels so that the timegate/bandwidth of the processor can "follow" the timeDoppler history of the signal (see Fig. 15), thus minimizing the inclusion of additional noise in the power measurement and minimizing $K_{P}$. A second advantage of multichannel processing is that it reduces the size and complexity of the FFT processor. The frequency resolution in the DDP is driven by $\sigma_{0}$ cell resolution and location requirements. To meet NSCAT mission requirements the maximum $\sigma_{0}$ cell location error must be less than $4 \mathrm{~km}$ in crosstrack distance. This corresponds to Doppler shifts of 500 and $200 \mathrm{~Hz}$ at the near and far swaths, respectively. The frequency resolution 


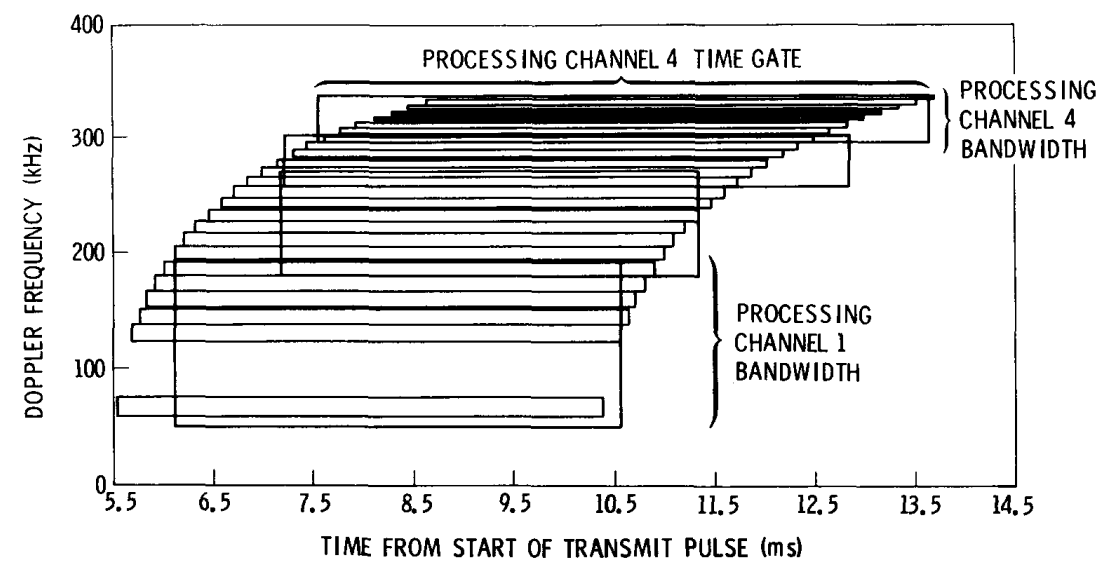

MULTI - CHANNEL

Fig. 15. The time gates and bandwidths of the four processing channels at the output of the NSCAT RFS superimposed on an example of Doppler history.

requirements dictate the spacing of the FFT bin center frequencies, and hence the signal sample rate. The different frequency resolution requirements can be used to reduce the DDP complexity by splitting the processing bandwidth into unequal channels. By using a wider bandwidth channel (resulting in a reduced frequency resolution) for the near swath than for the far swath, the same FFT length can be used for all processing channels and FFT hardware can be timeshared between channels.

The DDP contains a specialized 16-b FFT processor capable of computing 7 complex 512-point FFT's in $16 \mathrm{~ms}$. This processor is time-shared between the channels. Each baseband channel from the RFS is digitized with an 8-b A/D converter at the sample rate given in Table 2. As described in [18], the start of the sampling and the number of samples for each channel is optimized for the signal characteristics. DDP timing signals are derived from a $16-\mathrm{MHz}$ clock using a custom sequencer built in CMOS LSI logic.

Key characteristics of the NSCAT DDP are summarized in Table 2. The number of channels, the bandwidth of each channel, and the 512-point FFT size were selected to minimize $K_{P}$ and remain within the computational limitations of available space-qualified hardware. The channel bandwidths are roughly in the proportion of $4: 2: 1: 1$.

The DDP performs complicated signal processing which could in principle be done on the ground; however, the downlink data rate is reduced by a factor of 2500 by performing it onboard. At the end of each 468-ms antenna beam dwell time, $48\left(24 P_{(s+n)}\right.$ and $\left.24 P_{n}\right)$ 16-b power measurements are formatted by the $\mathrm{CP}$ and transmitted to the ground for further processing. The CP produces a 1376-b telemetry frame once every measurement frame (Fig. 9), leading to a total data rate for the instrument of $3.2 \mathrm{~kb} / \mathrm{s}$.

\section{GRoUND PRocessing}

As discussed in Section II, scatterometer measurements of wind velocity are highly indirect, and significant processing is necessary in order to retrieve vector winds from the directly measured backscattered power. This section describes the NSCAT Data Processing and Instrument Operations (DP\&IO) system as an example to illustrate the levels of processing required to derive various wind products from the measured backscattered power.

Calculation of vector winds from raw NSCAT data requires: 1) calculation of earth-located $\sigma_{0}$ values for each antenna beam and combining colocated ocean $\sigma_{0}$ measurements from beams with different azimuths; 2) estimation of a set of probable vector winds from the colocated $\sigma_{0}$ measurements through inversion of the model function and statistical solution of an overdetermined system; and 3) selection of a unique wind vector from the set of probable wind vectors.

Inputs to the DP\&IO consist of NSCAT telemetry (radar return, calibration, and instrument engineering data), spacecraft orbit and attitude data, and additional geophysical data used primarily to flag $\sigma_{0}$ cells for the presence of ice and excess atmospheric water. The outputs are geophysically useful swath-oriented global $\sigma_{0}$ measurements, ocean vector winds, and spatially and temporally averaged gridded wind field maps (Table 3 ). This processing and the resulting data products are summarized in Fig. 16 and briefly described in the following subsections, followed by an outline of the hardware architecture of the DP\&IO system.

\section{A. $\sigma_{0}$ Calculation and Colocation}

After conversion of raw NSCAT telemetry to engineering units (Level 0 to Level 1), earth locations of $\sigma_{0}$ cell-centers and individual cell geometries are calculated using the spacecraft orbit and attitude data as well as the known instrument binning tables. Estimates of signal and noise power $\left(P_{s}\right.$ and $\left.P_{n}\right)$ in each cell are constructed from backscatter and receive-only power measurements. Given 
Table 2 Key NSCAT DDP Design Parameters

\begin{tabular}{lc}
\hline \multicolumn{2}{c}{ Key DDP Design Parameters } \\
\hline$\sigma_{0}$ cell spacing & $25 \mathrm{~km}$ \\
Cell location resolution & $4 \mathrm{~km}$ \\
Number of $\sigma_{0}$ cells & 25 \\
$\sigma_{0}$ bandwidth range & $1.8-15 \mathrm{kHz}$ \\
Maximum processing bandwidth & $450 \mathrm{kHz}$ \\
Maximum processing length & $11 \mathrm{~ms}$ \\
FFT size & 512 points \\
Data segment time-overlap & $50 \%(256$ samples $)$ \\
Antennas using spectral reversal & $2,3,4$ \\
\hline
\end{tabular}

\begin{tabular}{ccccccc}
\hline \multicolumn{7}{c}{ Individual Channel Timing and Bandwidth } \\
\hline $\begin{array}{c}\text { Channel } \\
\text { Number }\end{array}$ & $\begin{array}{c}\text { No. of FFT } \\
\text { Segments }\end{array}$ & $\begin{array}{c}T_{1} \\
(\mathrm{~ms})\end{array}$ & $\begin{array}{c}\text { Bandwidth } \\
\mathrm{kHz}\end{array}$ & $\begin{array}{c}\text { Center Freq. } \\
\mathbf{k H z}\end{array}$ & $\begin{array}{c}\text { Sample Freq. } \\
\mathbf{k H z}\end{array}$ & $\begin{array}{c}\text { Freq. Resolution } \\
\mathrm{Hz}\end{array}$ \\
\hline 1 & 7 & 6.464 & 209.041 & 141.103 & 483.781 & 945 \\
2 & 3 & 7.931 & 113.538 & 270.182 & 262.757 & 513 \\
3 & 2 & 8.030 & 58.506 & 337.716 & 135.400 & 264 \\
4 & 2 & 8.327 & 52.831 & 380.861 & 122.267 & 239 \\
\hline
\end{tabular}

DDP Integer Arithmetic Resolution

\begin{tabular}{lc}
\hline Processing stage & Bits \\
\hline Analog to digital conversion & 8 \\
FFT (complex) & 16 \\
Windowing (Hann window) & 18 \\
Squaring & 32 \\
Bin summation & 28 \\
Output floating-point exponent & 4 \\
Output floating-point mantissa & 12 \\
\hline
\end{tabular}

the signal power estimate $P_{s}$ and instrument engineering data on the antenna gains, system losses, and transmitted power, the radar equation (1) is used to calculate the normalized radar cross section for each cell of each antenna.

Since use of the $\sigma_{0}$ data for wind retrieval assumes that the data are acquired from ocean targets uncontaminated by ice and land, it is necessary to flag those $\sigma_{0}$ cells containing non-ocean artifacts. Additional flags are provided to identify instrument-related anomalies. The flagged timeand antenna beam-oriented $\sigma_{0}$ cells with all auxiliary data comprise the Level 1.5 data set (see Table 3); this data set is designed to be fully reversible in the event that reprocessing is required at a later time. Note that since the Level 1.5 data are global and at moderate $(25-\mathrm{km})$ resolution, the data set may have applications for scientific study of certain land and ice processes.

Since retrieval of vector winds from scatterometer data requires colocated, simultaneous $\sigma_{0}$ measurements from multiple azimuth angles, backscatter data from different antenna beams are colocated and re-ordered with respect to an earth-located grid centered on the satellite subtrack to generate the Level 1.7 data set (Table 3). These data are ocean-only and form the primary basis for wind retrieval processing.

\section{B. Wind Retrieval}

Much of the analysis of the Seasat data has centered on the wind retrieval from colocated, noisy $\sigma_{0}$ measurements,

Table 3 NSCAT Data Products

\begin{tabular}{|c|c|c|}
\hline & Description & Volume (MB/day) \\
\hline Level 0 & Time-ordered telemetry & 32.8 \\
\hline Level 1.5 & $\begin{array}{l}\text { Global } 25 \mathrm{~km} \sigma_{0} \text { organized by antenna } \\
\text { beam }\end{array}$ & 430.8 \\
\hline Level 1.7 & $\begin{array}{l}\text { Ocean-only } 25 \mathrm{~km} \sigma_{0} \text { colocated onto } \\
\text { subtrack grid }\end{array}$ & 130.6 \\
\hline Level 2.0 & $\begin{array}{l}\text { Probable } 50-\mathrm{km} \text { wind vectors swath } \\
\text { organization, unique vector chosen by } \\
\text { ambiguity removal routine is flagged }\end{array}$ & 19.9 \\
\hline Level 3.0 & $0.5^{\circ} \times 0.5^{\circ} \times 1$ day wind field map & 3.4 \\
\hline
\end{tabular}




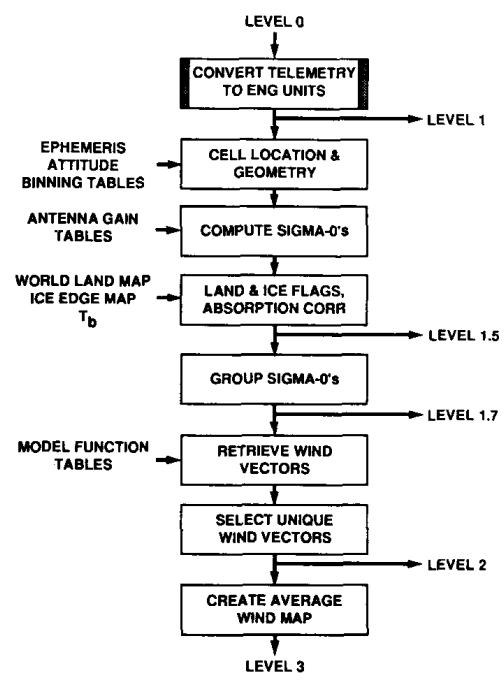

Fig. 16. Major ground processing operations and data products for NSCAT science data.

and several wind retrieval techniques have been developed by different investigators. As discussed in Section II, wind retrieval involves inversion of the model function (see (2)) and identification and ranking of the (near) solutions obtained by solving the overdetermined system for wind speed and direction. Profiting by the Seasat experience, the NSCAT wind retrieval technique utilizes a maximum likelihood estimation of wind velocity based on the measured $\sigma_{0}$ and estimated noise data [4], [26].

Typically $16 \sigma_{0}$ estimates are available for each $50 \times 50$ $\mathrm{km}$ vector wind cell on the ocean surface (each $\sigma_{0}$ cell is $25 \times 25 \mathrm{~km}$, and cells are available from each of the four antenna beams). Solution of the geophysical model function involves determining the wind speeds and directions that are statistically consistent with the 16 measured but noisy $\sigma_{0}$ values. Application of classic maximum likelihood techniques results in determining the wind speeds and directions that maximize the objective function:

$$
J(|U|, \phi)=\sum_{i=1}^{N}\left|\frac{\left(\hat{\sigma}_{o i}-\sigma_{o i}\right)}{\delta_{i}}\right|^{2}+\ln \delta_{i}^{2}
$$

where $\hat{\sigma}_{o i}$ are the measured values, $\sigma_{o i}$ are the "true" values corresponding to the wind velocity at the appropriate polarization and azimuth/incidence angles (obtained from (2)), and $\delta_{i}^{2}=\operatorname{var}\left[\sigma_{o i}\right]$ associated with the true $\sigma_{0}$ (calculated from the known characteristics of the digital filter; see [18]) used to weight the contribution of each $\sigma_{0}$ to the objective function. A search through (speed, direction) space typically results in several distinct maxima, corresponding to near intersections of the curves shown schematically in Fig. 5. The relative values of the objective function at each maximum are used to approximately rank the likelihood of the solution, with larger values corresponding to "closer" intersections and hence more probable solutions.

Recognizing the empirical nature of the model function itself, the NSCAT wind retrieval scheme relies only on a general tabular model function containing $\sigma_{0}$ values for each wind speed $(1 \mathrm{~m} / \mathrm{s}$ resolution), incidence angle $\left(2^{\circ}\right.$ resolution), and azimuth angle $\left(5^{\circ}\right.$ resolution), with trilinear interpolation between table entries. This tabular model function form also allows additional dimensions to be added (e.g., for sea-surface temperature or geographical location), corresponding to effects of non-wind variables that are also independent of the wind velocity. By utilizing the tabular form, the wind retrieval is decoupled from the model function, thus allowing postlaunch changes to the model function without requiring modification of the retrieval code.

\section{Ambiguity Removal}

A major drawback of the Seasat scatterometer data was the fact that selection of a unique wind direction was not possible using scatterometer data alone. The addition of two antenna beams on each side of the spacecraft subtrack greatly ameliorates this problem for NSCAT. The NSCAT data processing thus includes an automated ambiguity removal scheme based on the median filter concept [29], with the aim of selecting from the set of probable vectors at each location that vector which is closest to the true wind velocity. The median filter scheme to be implemented for NSCAT is discussed in detail in [30] and only briefly summarized below.

Each swath is considered separately, and an initial guess field is constructed using the highest probability vectors resulting from the wind retrieval process at each location. A centered $7 \times 7$ element filter (corresponding to $350 \times 350 \mathrm{~km}$ in physical space) is used to calculate the value $E_{i j}^{k}$ at location $(i, j)$ for each of the probable vectors $\boldsymbol{A}_{i j}^{k}$ according to

$$
E_{i j}^{k}=\left(L_{i j}^{k}\right)^{-2} \sum_{m=i-3}^{i+3} \sum_{n=j-3}^{j+3}\left\|A_{i j}^{k}-U_{m n}\right\|
$$

where $L_{i j}^{k}$ is the likelihood associated with the probable vector of rank $k$ at the central location, and $U_{m n}$ are the vectors at each of the other locations of the filter. The ambiguity $\boldsymbol{A}_{i j}^{k}$ which minimizes $E_{i j}^{k}$ is then substituted for the next iteration, the filter is moved in space, and the process is repeated until all locations have been examined. The filter is applied repeatedly until convergence is reached.

Extensive testing of the procedure using a variety of realistic wind fields and simulated wind retrievals from noisy $\sigma_{0}$ measurements has shown that ambiguity removal skills in excess of $96 \%$ are achieved. However, recognizing the ultimate inaccuracies of all automated ambiguity removal schemes, the Level 2.0 product (Table 3 ) contains all probable wind vectors at each location with a flag indicating the vector chosen by the automated ambiguity removal scheme. After further analysis, geophysical investigators 
can perform their own ambiguity removal without the need to also carry out the computationally intensive wind retrieval process.

The final geophysical product is a wind field map (Level 3; see Table 3) representative of averages over $0.5^{\circ} \times 0.5^{\circ}$ spatial extents and daily time periods. Although specific geophysical investigations will require tailored interpolation/extrapolation schemes which minimize errors on "important" scales of variability (see, for instance, [16]), it was not deemed possible to provide a multiplicity of gridded products within the auspices of the NSCAT Project. Based on simulations and extensive consultation with the NSCAT Science Team, a simple average derived from binning the swath-oriented data (and including values for means and mean-squared component wind speeds) would have the greatest utility from both a "quick-look" standpoint as well as forming the basis for significantly longer temporal averages required for largescale oceanographic studies (see [3] for an example using Seasat data).

\section{System Development and Architecture}

The level-conversion processing described above is computationally intensive, particularly in the area of wind retrieval. The need to minimize computation time in order to allow non-backlog processing of scatterometer data has dominated past algorithm development efforts, and has occasionally led to suggestions that accuracy be traded for reduced computational complexity. While these concerns were very real in the past, rapid progress in commercial computing technology has greatly diminished the severity of the processing problem and decreased the cost of the planned NSCAT DP\&IO hardware.

The science processing algorithms described above have been fully coded and tested. Definition of all products and intermediate file structures has allowed the separate algorithms to be interfaced into a single testbed that performs processing from Level 1 through Level 3. The testbed contains approximately 5000 lines of executable code. Since the algorithms were coded in standard Fortran and $\mathrm{C}$, the testbed is easily transported, allowing realistic benchmarking of potential hardware configurations with minimal effort.

In order to insure the ability to fully process the NSCAT data with no backlog, the DP\&IO system is designed to process a full week of input data in 5 days ( 2 shifts/day). This corresponds to fully reducing and processing each raw data frame in $250 \mathrm{~ms}$. Based on testbed benchmarks and conservative extrapolations (and accounting for data ingestion, organization, cataloging and control), these calculations will require computing power equivalent to approximately 7 VAX 11/785 machines. Such computational power (and associated memory, disk storage, and intermachine communication capabilities) is clearly available now in the form of workstations, and it is planned to implement the full NSCAT DP\&IO system on a series of such stations connected via a local area network.

\section{SCATTERometers IN the NeXT DeCade}

Although the brief flight of Seasat in 1978 clearly demonstrated that spaceborne scatterometry could provide accurate measurements of near-surface winds over the global oceans, programmatic difficulties in Western space agencies prevented any subsequent flights through the decade of the 1980 's. Nonetheless, the recognition in the scientific and operational communities of the value of scatterometer data has grown steadily, and the success of several large-scale experimental programs (e.g., the World Ocean Circulation Experiment, and the Joint Global Ocean Flux Study) hinges upon the future availability of scatterometer winds.

Both NASA and the European Space Agency have in place mature, achievable programs for scatterometer missions through the 1990's and beyond. The next scatterometer will be part of the ESA ERS-1 mission (to be launched in April 1991) and is described in detail by Attema in this issue. Operating at $\mathrm{C}$-band and vertical polarization, it will acquire $50-\mathrm{km}$ resolution data in a single $500-\mathrm{km}$ wide swath using three fan-beam antennas at $45^{\circ}, 90^{\circ}$, and $135^{\circ}$ angles to the spacecraft velocity vector. A ground processing system will process the data to unique wind vectors and provide them to selected operational meteorological agencies within $3 \mathrm{~h}$ of acquisition. Precision non-real-time processing will be used to generate a research-quality vector wind data set with a delay of several weeks. The ERS-1 scatterometer will be the first spaceborne scatterometer to operate at C-band (and thus extensive model function refinement activities are anticipated postlaunch); in addition, the design of the ERS-1 AMI instrument precludes operation of the scatterometer mode when the SAR is acquiring data in image mode, resulting in somewhat decreased coverage (over time), especially in the northern hemisphere. An identical single-swath, C-band, fan-beam scatterometer system is planned for the ESA ERS-2 follow-on mission to be launched in 1994.

As described above, the two-swath Ku-band NSCAT instrument will be launched in 1995 as part of the NASDA ADEOS mission. The significant overlap between the ERS-2 and ADEOS missions will allow, for the first time, on-orbit co-calibration of the two scatterometers; since they operate at different frequencies, exciting possibilities exist to gain significantly increased understanding of the scattering mechanisms and physical basis of scatterometry. In addition, the increased overall coverage afforded by two scatterometers will aid in the construction of accurate synoptic and time-averaged vector wind fields.

Both ESA and NASA plan to continue flights of scatterometers as part of the Earth Observing System missions scheduled for 1998 and beyond. At present, NASA plans to fly NSCAT-class, fan-beam systems at Ku-band, while ESA will fly a C-band system upgraded to acquire data in two swaths and to operate continuously (independent of any other instrument mode). The long-term availability of data from both scatterometers will afford greatly increased coverage relative to any single instrument, and will signifi- 
cantly decrease sampling-related errors in derived products on time scales shorter than 1 month (cf. [2]).

During the past decade, scatterometer designs have been formulated that ameliorate drawbacks associated with the classical fan-beam approach. As first proposed by Kirimoto and Moore [17], see also [19], two, conically scanning pencil beam antennas (at different incidence angles) can be used to acquire backscatter data. Because inner and outer scans overlap as the spacecraft propagates, backscatter measurements are obtained from both scans at cross-track distances less than the radius of the inner scan. Furthermore, each scan images a point on the surface twice-once when the ocean location is "ahead" of the subsatellite point, and once when the satellite has passed. Thus four backscatter measurements ( 2 different azimuths at each of two different incidence angles) are obtained for each point within the inner scan radius. Beyond the inner scan, two measurements are obtained from the outer scan alone. By combining the backscatter measurements for each ocean location, the surface wind velocity can be estimated as in classical scatterometry.

The scanning scatterometer concept has several advantages over traditional fan-beam instruments, including continuous swaths with no nadir gap, high $\sigma_{0}$ measurement accuracy, and high directional accuracy. Because measurements are made at only a small number of incidence angles, the model function does not need to be known over a wide range of radar parameters. However, although the scanning scatterometer concept is extremely promising and has been well studied, there are at present no firm plans to orbit such an instrument in this century.

\section{ACKNOWLEDGMENT}

The authors thank Carroll Winn, R. Scott Dunbar, and other members of the NSCAT Project Staff for helpful comments on early drafts of this manuscript. This research was performed at the Jet Propulsion Laboratory, California Institute of Technology, under contract with the National Aeronautics and Space Administration.

\section{REFERENCES}

[1] R. Atlas, et al., "Global surface wind and flux fields from model assimilation of Seasat data," J. Geophys. Res., vol. 92, pp. 6477-6487, 1987.

[2] D. B. Chelton and M.H. Freilich, "Sampling errors in scatterometer and altimeter data," U.S. WOCE Planning Rep. \#1, pp. $69-84,1985$.

[3] D. B. Chelton, A. Mestas-Nunez, and M.H. Freilich, "Global wind stress and Sverdrup circulation from the Seasat scatterometer," J. Phys. Oceanogr., vol. 20, pp. 1175-1205, 1990

[4] C.-Y. Chi and F. K. Li, "A comparative study of several wind estimation algorithms for spaceborne scatterometers," IEEE Trans. Geosci. Remote Sensing, vol. 26, pp. 115-121, 1988.

[5] M. C. Colton, "Dependence of Radar Backscatter on the Energetics of the Air-Sea Interface," Ph.D. dissertation, Naval Postgraduate School, Monterey, CA, 1989.

[6] M. A. Donelan and W.J. Pierson, "Radar scattering and equilibrium ranges in wind-generated waves with application to scatterometry," J. Geophys. Res., vol. 92, pp. 4971-5029, 1987.

[7] R.E. Fischer, "Standard deviation of scatterometer measurements from space," IEEE Trans. Geosci. Electron., vol. GE-10, pp. 106-113, 1972.
[8] M.H. Freilich and D.B. Chelton, "Wavenumber spectra of Pacific winds measured by the Seasat scatterometer," J. Phys. Oceanogr., vol. 16, pp. 741-757, 1986.

[9] R.E. Glazman, G. G. Pihos, and J. Ip, "Scatterometer wind speed bias induced by the large-scale component of the wave field," J. Geophys. Res., vol. 93, pp. 1317-1328, 1988.

[10] W.L. Grantham, et al., "The Seasat-A satellite scatterometer," IEEE J. Oceanic Eng., vol. OE-2, pp. 200-206, 1977.

[11] W. L. Grantham, E. M. Bracalente, C. L. Britt, Jr., F. J. Wentz, W. L. Jones, Jr., and L.C. Schroeder, "Performance evaluation of an operational spaceborne scatterometer," IEEE Trans. Geosci. Remote Sensing, vol. GE-20, July 1982

[12] A. T. Jessup, W. C. Keller, and W. K. Melville, "Measurements of sea spikes in microwave backscatter at moderate incidence," J. Geophys. Res., vol. 95, pp. 9679-9688, 1990.

[13] J.W. Johnson, et al., "Seasat-A satellite scatterometer instrument evaluation," IEEE J. Oceanic Eng., vol. OE-5, pp. 138-144, 1980.

[14] W. L. Jones, L. C. Schroeder, and J. L. Mitchell, "Aircraft measurements of the microwave scattering signature of the ocean," IEEE J. Oceanic Eng., vol. OE-2, pp. 52-61, 1977.

[15] W. L. Jones, et al., "The Seasat-A satellite scatterometer: the geophysical evaluation of remotely sensed winds over the ocean," J. Geophys. Res., vol. 87, pp. 3297-3317, 1982.

[16] K. A. Kelly and M.J. Caruso, "A modified objective mapping technique for scatterometer wind data," J. Geophys. Res., vol. 95 , pp. $13,483-13,496,1990$.

[17] T. Kirimoto and R. K. Moore, "Scanning wind-vector scatterometers with two pencil beams," in Proc. Conf. on Remote Sensing of Oceans and Atmospheres, NASA Conf. Pub. 2303, pp. 89-97, 1985.

[18] D. G. Long, C.-Y. Chi, and F. K. Li, "The design of an onboard digital Doppler processor for a spaceborne scatterometer," IEEE Trans, Geosci. Remote Sensing, vol. 26, pp. 869-878, 1988.

[19] D. G. Long, M. H. Freilich, D. F. Leotta, and D. E. Noon, "A scanning scatterometer for the EOS polar platform," in Proc. Int. Geoscience and Rem. Sens. Symp., College Park, MD, pp. 2447-2450, 1990

[20] D. G. Long and J.M. Mendel, "Identifiability in wind estimation from scatterometer measurements," IEEE Trans. Geosci. Remote Sensing, vol. 29, pp. 268-276, Mar. 1991

[21] R. K. Moore and W.J. Pierson, "Measuring sea state and estimating surface winds from a polar orbiting satellite," in Proc. Int. Symp. on Electromagnetic Sensing of Earth from Satellites, Miami Beach, FL, 1966.

[22] R. K. Moore and A. K. Fung, "Radar determination of winds at sea," Proc. IEEE, vol. 67, pp. 1504-1521, 1979.

[23] J. J. O'Brien et al., Scientific Opportunities Using Satellite Wind Stress Measurements Over the Ocean. Fort Lauderdale, FL: N.Y.I.T. Press, 1982.

[24] W.J. Pierson, "Examples of, reasons for, and consequences of the poor quality of wind data from ships for the marine boundary layer: Implications for remote sensing," J. Geophys. Res., vol. 95, pp. 13,313-13,340, 1990.

[25] W. J. Pierson, Jr., "The measurement of the synoptic scale wind over the ocean," J. Geophys. Res., vol. 88, pp. 1682-1708, 1983.

[26] W.J. Pierson, "A Monte Carlo comparison of the recovery of winds near upwind and downwind from the SASS-1 model function by means of the sum of squares algorithm and a maximum likelihood estimator," NASA Contractor Rep. 3839, 1984.

[27] W. J. Plant and W.C. Keller, "Evidence of Bragg scattering in microwave Doppler spectra of sea return," J. Geophys. Res., vol. 95 , pp. 16,299-16,310, 1990.

[28] L. C. Schroeder, et al., "The relationship between wind vector and normalized radar cross-section used to derive SeasatA satellite scatterometer winds," J. Geophys. Res., vol. 87, pp. $3318-3386$.

[29] H. Schultz, "A circular median filter approach for resolving directional ambiguities in wind fields retrieved from spaceborne scatterometer data," J. Geophys. Res., vol. 95, pp. 5291-5303, 1990.

[30] S. J. Shaffer, et al., "A median-filter-based ambiguity algorithm for NSCAT," IEEE Trans. Geosci. Remote Sens., vol. 29, pp. 167-174, Jan. 1991

[31] R.H. Stewart, Methods of Satellite Oceanography, Univ. of Calif. Press, San Diego, CA, 360 pp., 1985. 
[32] F. T. Ulaby, R. K. Moore, and A. K. Fung, Microwave Remote Sensing: Active and Passive, Addison-Wesley Pub. Co., vols. I, II, 1981, 1982; vol. III, Artech House, 1986.

[33] F.J. Wentz, S. Peteherych, and L. A. Thomas, "A model function for ocean radar cross sections at $14.6 \mathrm{GHz}$," J. Geophys. Res., vol. 89, pp. 3689-3704, 1984.

[34] F. J. Wentz, L. A. Mattox, and S. Peteherych, "New Algorithms for microwave measurements of ocean winds: Applications to SEASAT and the Special Sensor microwave imager," J. Geophys. Res., vol. 91, pp. 2289-2307, 1986.

[35] P. M. Woiceshyn, et al., "The necessity for a new parameterization of an empirical model for wind/ocean scatterometry," J. Geophys. Res., vol. 91, pp. 2273-2288, 1986.

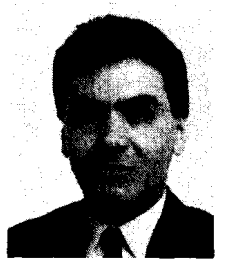

Firouz Naderi (Senior Member, IEEE) received the B.S. degree from Iowa State University, Ames, in 1969 and the M.S. and Ph.D. degrees from the University of Southern California, Los Angeles in 1972 and 1976, respectively, all in electrical engineering.

Currently, he is the Project Manager for the Spaceborne Scatterometer Projects Office at JPL where he manages both the NASA Scatterometer (NSCAT) Project and the STIKSCAT Project. He has been with the JPL since 1979, first as a communications satellite systems engineer and then as a manager in various technical positions. From 1986 to 1988 he accepted an assignment in NASA Headquarters to manage the Advanced Communications Technology Satellites (ACTS) Program. Before that, he managed the NASA Mobile Satellite Experiment (MSAT-X) at JPL where he led design and development of technologies needed for the first generation mobile satellites-an activity which earned the JPL Team NASA's Distinguished Group Achievement Award.

Dr. Naderi is a senior member of AIAA and a member of Sigma Chi and Eta Kappa Nu.

Michael H. Freilich received the B.S. degrees in both physics (honors) and chemistry from Haverford College, Haverford, PA in 1975 and the Ph.D. degree in oceanography from Scripps Institution of Oceanography, University of California, San Diego in 1982.

He was an Assistant Professor at the Marine Sciences Research Center, State University of New York in 1982. In 1983 he joined the Jet Propulsion Laboratory as a member of the Oceanography Group. Presently, he is Project Scientist for NSCAT, as well as a Principal Investigator on the ESA ERS-1 mission and the Principal Invest- igator for the NASA STIKSCAT instrument to fly on EOS. In addition to geophysical applications of scatterometer wind data, his scientific interests include modeling of nonlinear surface waves in shallow water and investigations of wave-induced nearshore fluid motions. He has served as a referee for numerous oceanographic journals and as Associate Editor for the Journal of Geophysical Research (Oceans)

Dr. Freilich received a JPL Director's Research Achievement Award in 1988

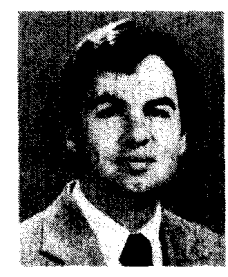

David G. Long (Member, IEEE) received the B.S. and M.S. degrees in electrical engineering from Bringham Young University, Provo, Utah in 1982 and 1983, respectively. He received the Ph.D. degree in electrical engineering from the University of Southern California, Los Angeles in 1989

From 1983 to 1990 he was with Caltech's Jet Propulsion Laboratory as a radar systems engineer. He was the Project Engineer for the NASA Scatterometer (NSCAT) project and the Experiment Manager for the EoS SCANSCAT. He was responsible for the high level design, analysis, and technical management of these projects to insure that the projects met all mission requirements. His responsibilities included overseeing instrument design and fabrication, algorithm and coding for the ground processing system, mission operations, and data analysis. His technical responsibilities included system performance analysis, high-level design, development and maintenance of system requirements, and supervision of the Systems Engineering staff. He was also a group leader supervising a staff of system engineers working on a number of JPL flight projects. Presently, he is an Assistant Professor in the Electrical and Computer Engineering Department at Brigham Young University. His research interests include computer graphics, signal processing, estimation theory, radar, and mesoscale atmospheric dynamics.

Dr. Long has received the NASA Award of Achievement several times and is a member Sigma Xi and Tau Beta Pi. 